\title{
An alternative approach with a low dose and prolonged chemotherapy for palliative treatment of locally advanced, metastatic or recurrent squamous cell head and neck cancer
}

\author{
Rohit Bishnoi ${ }^{1} \mathbb{D}$, Chintan Shah' ${ }^{1}$, Harini Bejjanki ${ }^{1}$, Jeffery A. Bennett ${ }^{3}$ and David N. Reisman ${ }^{2,4^{*}}$
}

\begin{abstract}
Background: It is expected that about 65,000 new patients will be diagnosed with head and neck cancer in 2017 in the United States. Patients with recurrent or advanced or metastatic head and neck do not have good survival due to aggressive and recurrent nature of this cancer. Moreover, cumulative and residual toxicities from previous and ongoing treatments significantly impede quality of remaining part of their life. Currently available chemotherapeutic regimens for this group are derived from the treatments used for the potentially curable disease. These regimens and associated toxicity are obviously not the best matches for the treatment with palliative intent. We here present a retrospective study where we used dose-adjusted chemotherapy specifically for palliative treatment this sub-group of head and neck cancer patients.
\end{abstract}

Methods: Study population was identified from the University of Florida, and IRB approval was obtained. We used currently available and approved chemotherapeutic agents (including Taxols, Platins, 5-Fluorouracil and Epidermal Growth Factor Receptor inhibitors) for treatment of head and neck cancer but dose-adjusted at approximate 50\% dose of currently recommended doses. We then gave personalized doses for a prolonged period by titrating doses based on response and tolerability of each patient. Data was collected for treatment, response, side effects, and outcomes. KM analysis was performed for survival data.

Results: Total of 32 patients were included in this study with a median age of 65.2 years and a median follow-up of 10.1 months. 62.5\% $(n=20)$ had locally advanced disease and rest had metastatic disease. 37.5\% $(n=12)$ had new disease while rest had recurrent cancer. Of 32 patients, 14 patients received TPF based while 18 patients received PFE based chemotherapy. Total of 270 chemotherapy cycles were delivered among these 32 patients. They received a median of 9 cycles (range 3-14) over a median of 6.2 months (range 1.8-21.1). With this treatment approach, we noted median progression-free survival of 14.0 months and median overall survival of 15.7 months. Notable grade 3 toxicities were generalized fatigue in 12.5\% ( $(n=4)$, nausea/vomiting in 6.3\% $(n=2)$, diarrhea in in $6.3 \%(n=2)$, mouth soreness in $6.3 \%(n=2)$, rash in $3.1 \%(n=1)$, neutropenia in $18 \%(n=6)$ and anemia in $15.6 \%(n=5)$ while notable grade 4 toxicities were neutropenia and anaphylaxis in $3.1 \%(n=1)$ patient each.

(Continued on next page)

\footnotetext{
* Correspondence: reisman2010@gmail.com

${ }^{2}$ Baptist Medical Group - Hematology Oncology, 1717 North E Street Tower

3, Suite 231, Pensacola 32501, Florida, USA

${ }^{4}$ Department of Medicine, University of Florida, PO Box 100278, 1600 SW

Archer Rd, Gainesville, Florida 32610, USA

Full list of author information is available at the end of the article
} 
(Continued from previous page)

Conclusion: With this personalized approach, we noticed minimal side effects, able to deliver prolonged therapy and obtained comparable results to previous studies.

Keywords: Dose-adjusted chemotherapy, Metronomic chemotherapy, Advanced head and neck cancer, Low-dose chemotherapy, Recurrent head and neck cancer, Personalized chemotherapy

\section{Background}

It is expected that about 65,000 new patients will be diagnosed with Head and neck cancer in 2017 in the United States [1]. The five-year overall survival rates for all stages of head and neck cancer has improved from about $53 \%$ in 1980 's to $66 \%$ in early 2000's [2]. $40 \%$ of patients present in limited or early stage (stage I and II) where treatment can be curative by surgery or radiation alone [3]. While patients presenting in locally advanced or metastatic stage treatment is usually multimodal involving radiation and chemotherapy as well. This group of head and neck cancer with the advanced, recurrent or metastatic disease has poor median survival of less than 1 year [4-6]. Per National Comprehensive Cancer Network (NCCN) guidelines, platinum-based drug regimens in combination with a taxane, 5-fluorouracil, and epidermal growth factor receptor (EGFR) inhibitors remains front-line therapy in patients with good performance status [5, 7-11]. Triple regimen TPF (including taxol, platin, and 5-FU) or PFE (including Platin, 5-FU, and EGFR inhibitor) are frontline regimen especially for advanced and metastatic cancer $[6,10,11]$.

Unfortunately, many patients with recurrent or incurable head and neck cancers have been treated over periods of months to years with chemotherapy, radiation and/or surgery at some point they focus on the quality of life over longevity. This is particularly true for those patients, who had to endure debilitating effects of head/ neck surgery or patients who undergo high-dose radiation therapy which results in the severe dry mouth, caries, osteonecrosis of the jaw among a cadre of other adverse side effects. This is an important factor in deciding whether or not they would pursue any further or additional therapy [12, 13]. As such, patients offered standard dose chemotherapy (outlined in the NCCN guidelines) are faced with a slew of not uncommon drug toxicities. These standard dose regimens with 2 to 3 drug combination, can only be used for short duration and are typically limited up to 4 cycles (rarely 6) due to associated toxicities $[5,7,11,14]$. While such treatment strategies can shrink cancers in incurable disease, these approaches are only of limited therapeutic value given their limited duration.

While developing cancer treatment regimens, phase I and phase II trials are designed to identify maximum tolerated dose (MTD) with acceptable grade 3 and four toxicity. In general, oncology axiom has been that dose, and clinical response has a linear relationship where higher dose gives superior responses. However, contrary to this belief is the concept of dose adjusted or low-dose chemotherapy has been used for squamous cell head and neck cancers, where lower dosages as compared to MTD has been reported to be equally effective with much minimal significant side effects and thus aiming for better quality of life while undergoing chemotherapy. [15-20]. This is often why patients with advanced disease and poor functional status are also considered for single drug therapy or best supportive care $[3,21]$. Similarly, a metronomic approach where low-dose chemotherapy is administered continuously or at frequent intervals has been studied in a variety of cancers including breast, central nervous system cancers, lung cancer, hepatocellular cancer, colorectal cancer as well as head and neck among many other cancers [22-25]. Metronomic chemotherapy is still in evolution ever since it was first reported [26] and dosing schedules have been variable in each of these studies [22-25]. These alternative approaches can be defined personalized medicine which can afford same benefits as compared to conventional chemotherapy based on MTD [27].

Similarly in our practice, several of our patients with advanced disease would not pursue further treatment unless we could promise them little to no side effects and a reasonable quality of life with offered chemotherapy. We accepted this challenge and together carved out a personalized chemotherapeutic plan to accomplish this. We began down this pathway by reducing the standard doses as per NCCN recommendations by half so that we could avoid side effects while giving chemotherapy and maintaining patient's quality of life. Our initial goal was to raise the dosing up to a point where the patients began to get side effects as to maximize the dose given and potentially the response rate. However, we serendipitously found that majority of these patients started on lower doses responded in equivalence to standard doses and thus not needing escalation to standard doses. Herein, we report the results of our 32 patients who received this low dose chemotherapy using commonly used Food and Drug Administration (FDA) approved chemotherapeutic drugs, including Taxols, Platins, 5-Fluorouracil and EGFR inhibitors, but at a lower dose. Using this lower dose regimen, we achieved equal or 
better outcomes as compared to standard dosing and where patient's had little to no side effects (level 3/4).

\section{Methods \\ Ethical approval}

This retrospective study was done at the University of Florida. All standard ethical guidelines were followed in accordance with the Declaration of Helsinki, and full waiver of consent was obtained as per approval from University of Florida institutional review board (IRB201500105).

\section{Study population}

The study population was identified from University of Florida/UF health clinic. Inclusion criteria included patients treated with a modified dose of TPF or PFE for palliative treatment. Included patients compromised of the adult population only who either had recurrent or newly diagnosed HNSCC and were not considered surgical candidates. All patients who received conventional dosing for curative intent were excluded.

\section{Treatment}

Patients were treated with FDA approved drugs for the treatment of squamous cell head and neck cancers. These patients were treated with current first-line drugs including taxanes (paclitaxel or docetaxel), platinum (cisplatin or carboplatin), 5-fluorouracil and EGFR (Cetuximab or panitumumab) inhibitors in either TPF or PFE chemotherapy regimens. Paclitaxel, cis-platin and Cetuximab were the main drug used in corresponding groups from taxanes, platinum and EGFR inhibitors respectively. These drugs were rarely substituted with other drugs in same drug group due to patient-related factors. We initiated standard first-line therapies starting approximately at $1 / 2$ or $50 \%$ normal dosing to where side effects can be avoided or minimized. Treating physician then closely monitored response with the documentation of tolerability subsequently doses were incrementally increased until the emergence of intolerable side effects and titrated after that. Patients were followed with clinical response, and radiological studies were performed at frequent intervals to monitor tumor status. As we mentioned earlier, dosing schedule with metronomic chemotherapy has been varied and empiric and thus unclear pharmacokinetic profiles [28]. Similarly, we selected $50 \%$ dosing as a starting point, but we further titrated up or down based on the individual patient profile.

\section{Statistical analysis}

Performance status of patients was measured using the Eastern Cooperative Oncology Group scale (ECOG) [29]. Clinical adverse events and drug toxicity were measured using National Cancer Institute Common Terminology
Criteria for Adverse Events (CTCAE; version 3.0) [30]. Radiologic studies were done, and tumor response was evaluated using Response Evaluation Criteria in Solid Tumors 1.0 criteria. The tumor volumes were calculated using the Visage Picture Archiving and Communication Systems. The outline of the enhancing portion of the tumor is traced freehand on each slice to calculate an area. The area on each slice is summed to calculate a volume.

Radiologic response was determined in terms of complete response (CR), partial response (PR), stable disease (SD) and progressive disease (PD) [31]. Additionally, near complete response ( $\mathrm{nCR}$ ) was defined as a decrease in tumor size of between 95 and $99 \%$, and pathologic complete response $(\mathrm{pCR})$ was defined as when radiological examination revealed residual disease at the tumor site, but a pathological examination of residual disease did not reveal any active cancer.

Disease control rate (DCR) was defined as the combination of $\mathrm{CR}, \mathrm{nCR}, \mathrm{PR}$, and $\mathrm{SD}$. Overall response rate (ORR) was defined as the combination of CR, nCR, and PR. OS was defined as the interval between the beginnings of the first cycle of chemotherapy to the last follow-up or death from any cause. Progression-freesurvival (PFS) was defined as the time interval between initiation of chemotherapy and documentation of progression or censored at the time of death or the final follow-up in surviving patients without progression. SPSS software (IBM SPSS, Armonk, NY, USA) was used to calculate OS and PFS using Kaplan-Meier estimates.

\section{Results}

This retrospective study included 32 patients with squamous cell head and neck cancer. Median age was 65.21 years (range $50.62-79.50$ ). Of these 32 patients 28 $(87.5 \%)$ were males and $4(12.5 \%)$ were females. 12 (37.5\%) patients had newly diagnosed cancer while 20 (62.5\%) patients had recurrent disease. 20 (62.5\%) patients had loco-regional disease while 12 (37.5\%) patients had metastatic disease. Study data were collected from October 2013 to March 2017. Median follow-up time was 10.1 (range: 1.9-40.2) months after starting chemotherapy.

Thirty one patients had ECOG performance status was less than 2 while 1 patient had Eastern Cooperative Oncology Group (ECOG) status of 3. Of these $32 \mathrm{pa}-$ tients, $20(62.5 \%)$ patients had recurrent disease and were treated previously with either radiation, chemo, surgery or multimodality combination. Please refer to Table 1 for demographic details.

Using this low dose personalized chemotherapy, we were able to deliver a total of 270 chemotherapy cycles among these 32 patients. Median was 9 cycles with a range of minimum 3 cycles and maximum of 14 cycles. Of 32 patients, 14 patients received TPF based while 18 
Table 1 Demographic details

\begin{tabular}{|c|c|c|c|}
\hline Variables & sub-category & $n$ & $\%$ \\
\hline \multirow[t]{3}{*}{ Age (years) } & Median & 65.21 & \\
\hline & Minimum & 50.62 & \\
\hline & Maximum & 79.50 & \\
\hline \multirow[t]{2}{*}{ Sex } & Male & 28 & 87.5 \\
\hline & Female & 4 & 12.5 \\
\hline \multirow[t]{5}{*}{ ECOG } & 0 & 24 & 75.0 \\
\hline & 1 & 7 & 21.9 \\
\hline & 2 & 0 & 0.0 \\
\hline & 3 & 1 & 3.1 \\
\hline & 4 & 0 & 0.0 \\
\hline \multirow[t]{2}{*}{ Cancer status } & New & 12 & 37.5 \\
\hline & Recurrent & 20 & 62.5 \\
\hline \multirow[t]{2}{*}{ Cancer Extent } & Loco-regional & 20 & 62.5 \\
\hline & Metastatic & 12 & 37.5 \\
\hline \multirow[t]{3}{*}{ P-16 } & Not available & 16 & 50.0 \\
\hline & Positive & 8 & 25.0 \\
\hline & Negative & 8 & 25.0 \\
\hline
\end{tabular}

patients received PFE based chemotherapy. Of platin group, Cisplatin was mostly used and median dose used was $45 \mathrm{mg} / \mathrm{m} 2$ with a range of $20-75 \mathrm{mg} / \mathrm{m}^{2}$. Rarely carboplatin was used with median AUC (Area under the curve) of 3 , the range of 2-5 AUC. Among taxanes, paclitaxel was the main drug with a median dose of $80 \mathrm{mg} / \mathrm{m}^{2}$ (range $60-80 \mathrm{mg} / \mathrm{m}^{2}$ ), rarely nab-paclitaxel was used at a median dose of $80 \mathrm{mg} / \mathrm{m}^{2}$ (range 70$100 \mathrm{mg} / \mathrm{m}^{2}$ ). In certain patient-related clinical circumstances, docetaxel was used at a median dose of $32.5 \mathrm{mg} / \mathrm{m}^{2}$ (range $25-35 \mathrm{mg} / \mathrm{m}^{2}$ ). These substitutions were mostly related to patient-related factors. Median dose of 5 -FU was $360 \mathrm{mg} / \mathrm{m}^{2} /$ day (range $200-800 \mathrm{mg} / \mathrm{m}^{2} /$ day). Cetuximab was used at standard doses.

On first follow up study which was done at median interval of 3.5 months, out of 32 patients $12.5 \%$ $(n=4)$ patients achieved complete response (CR), $6.25 \%(n=2)$ achieved near complete response (nCR), 53.1\% $(n=17)$ achieved partial response (PR), $18.8 \%(n=6)$ achieved stable disease and rest $9.4 \%$ $(n=3)$ had progressive disease by Recist criteria. This corresponds to $90.6 \%$ disease control rate and $71.9 \%$ overall response rates.

At the end of study, 28.1\% $(n=9)$ patients had complete response $(\mathrm{CR}), 6.3 \%(n=2)$ patients had near complete response (nCR), 21.9\% $(n=7)$ patients had partial response (PR), 9.4\% $(n=3)$ patients had stable disease (SD) and $34.4 \%(n=11)$ patient had progressive disease (PD). This corresponds to $65.6 \%$ disease control rate (DCR) and $56.3 \%$ overall response rate (ORR). $40.6 \%(n=13)$ patients had expired by the end of the study while $6.25 \%(n=2)$ patients lost follow up and were censored at the last follow up date. Please see Table 2 for treatment response at initial and last followup study.

\section{Kaplan-Meier analysis}

We noted estimated median PFS was 14.0 months and median OS of 15.7 months. Please see Table 3 for comparative doses, cycles and results with other lank mark studies. Figure 1 shows KM estimate curves for PFS and OS.

\section{Tumor volumetric}

Tumor volumes measurements (Fig. 2) showed average tumor shrinkage by $50.6 \%$ at first follow-up and $60.9 \%$ on second follow-up studies which were done at a median interval of 3.5 and 6.2 months respectively. Tumor volume measurement was done on all available patients and was feasible in $90.6 \%(n=29)$ at 1 st follow-up and $78.1 \%(n=25)$ on 2 nd follow-up.

\section{Long-term benefits}

When these patients presented, surgical options were ruled out due to metastasis, locally advanced disease or due to previous surgery or radiation treatments in recurrent diseases. Due to radiologic complete or near-complete response to chemotherapy, a total of 6 (18.8\%) patients were later considered as a candidate for surgical exploration. No residual disease was found on pathologic examination but of these 6 patients, but 1 patient later relapsed with metastatic disease. One additional patient went for cryo-ablation and biopsy, and no pathologic disease was found. Altogether 6 (18.8\%) patients achieved pathologic complete response (pCR) where radiologic studies were still showing a complete or nearcomplete response, but pathological examination did not reveal any active tumor. Another $3(9.4 \%)$ patient were considered to be a complete response without the need of exploratory surgery based on radiologic findings. Thus

Table 2 Tumor response as per recist criteria at initial and last follow-up

\begin{tabular}{|c|c|c|c|c|}
\hline \multirow[t]{2}{*}{ Tumor response } & \multicolumn{2}{|c|}{$\begin{array}{l}\text { At } 1 \text { st follow-up study } \\
\text { (At median of } 3.5 \text { months) }\end{array}$} & \multicolumn{2}{|c|}{$\begin{array}{l}\text { At the end of study } \\
\text { (At median of } 10.1 \text { months }\end{array}$} \\
\hline & $n$ & $\%$ & $n$ & $\%$ \\
\hline$C R$ & 4 & 12.5 & 9 & 28.1 \\
\hline $\mathrm{nCR}$ & 2 & 6.3 & 2 & 6.3 \\
\hline$P R$ & 17 & 53.1 & 7 & 21.9 \\
\hline SD & 6 & 18.8 & 3 & 9.4 \\
\hline PD & 3 & 9.4 & 11 & 34.4 \\
\hline DCR & 29 & 90.6 & 21 & 65.6 \\
\hline ORR & 23 & 71.9 & 18 & 56.3 \\
\hline
\end{tabular}


Table 3 Shows a comparison of the dosage used, the number of cycles and reported survival of landmark studies and this study

\begin{tabular}{|c|c|c|c|c|c|c|}
\hline Drugs/cycles & $\begin{array}{l}\text { This study } \\
\text { (Median dose) }\end{array}$ & $\begin{array}{l}\text { EXTREME } \\
\text { regimen [7] }\end{array}$ & $\begin{array}{l}\text { TPEx } \\
\text { regimen [11] }\end{array}$ & $\begin{array}{l}\text { TPF } \\
\text { regimen [10] }\end{array}$ & $\begin{array}{l}P C E \\
\text { regimen [14] }\end{array}$ & $\begin{array}{l}\text { SPECTRUM } \\
\text { regimen [5] }\end{array}$ \\
\hline Paclitaxel mg/m² & 80 & & & & 100 & \\
\hline Docetaxel mg/m² & 32.5 & & 75 & 75 & & \\
\hline ClSplatin mg/m² & 45 & 100 & 75 & 75 & & 100 \\
\hline CARBOplatin AUC & 3 & 5 & & & 2.5 & \\
\hline $5 F U$ mg/m²/day & 360 & 1000 & & 750 & & 1000 \\
\hline Cetuximab mg/m² & 250 & 250 & 250 & & 250 & \\
\hline Panitumumab mg/kg & 3.5 & & & & & 9 \\
\hline Maximum cycles & 14 (median 9) & 6 & 4 & 4 & 6 & 6 \\
\hline PFS (months) & 14.0 (Cl: 5.3,22.6) & 5.6 & 14 & 11 & 5.2 & 5.8 \\
\hline OS (months) & 15.7 (Cl: 1.7, 29.7) & 10.1 & 6.2 & 18.8 & 14.7 & 11.1 \\
\hline
\end{tabular}

in total, $9(28.1 \%)$ patients achieved long-term benefits. Of $12(37.5 \%)$ patients who had metastatic disease at the beginning, $3(9.4 \%)$ patients achieved a complete response and while 1 patient achieved near-complete response radiographically without surgical intervention.

\section{Toxicity}

Very few patients endured grade 3 or 4 level toxicities. Notable high-grade toxicities were generalized fatigue in $12.5 \%(n=4)$, grade 3 neutropenia in $18 \%(n=6)$ and grade 4 neutropenia in 1 patient. Table 4 shows details of high grade toxicities observed in this study.

\section{Discussion}

Locally advanced or metastatic head and neck cancer is likely incurable disease if either surgery or radiation are not options. Despite the effectiveness of both of these modalities, these treatment methods do not afford patient cure to all. With head/neck cancer patients, a subset of these patients fails either one or both modalities or present with metastatic disease. In each of these cases, palliative or best supportive care is the only medical feasible option which may provide benefit. In these situations, when head/neck cancer is deemed to be a terminal condition, quality of life (QOL) becomes principal factor in any further medical decision-making. FDA recently approved Pembrolizumab and Nivolumab for a patient with advanced Squamous Cell Carcinoma of the Head and Neck (SCCHN) and who failed platinum-based therapy, pembrolizumab has shown a good benefit in patients who failed platinum-based therapy [32]. Usually, these drugs are reserved for a patient who failed standard therapy and where we are looking for improved survival with reasonable quality of life but

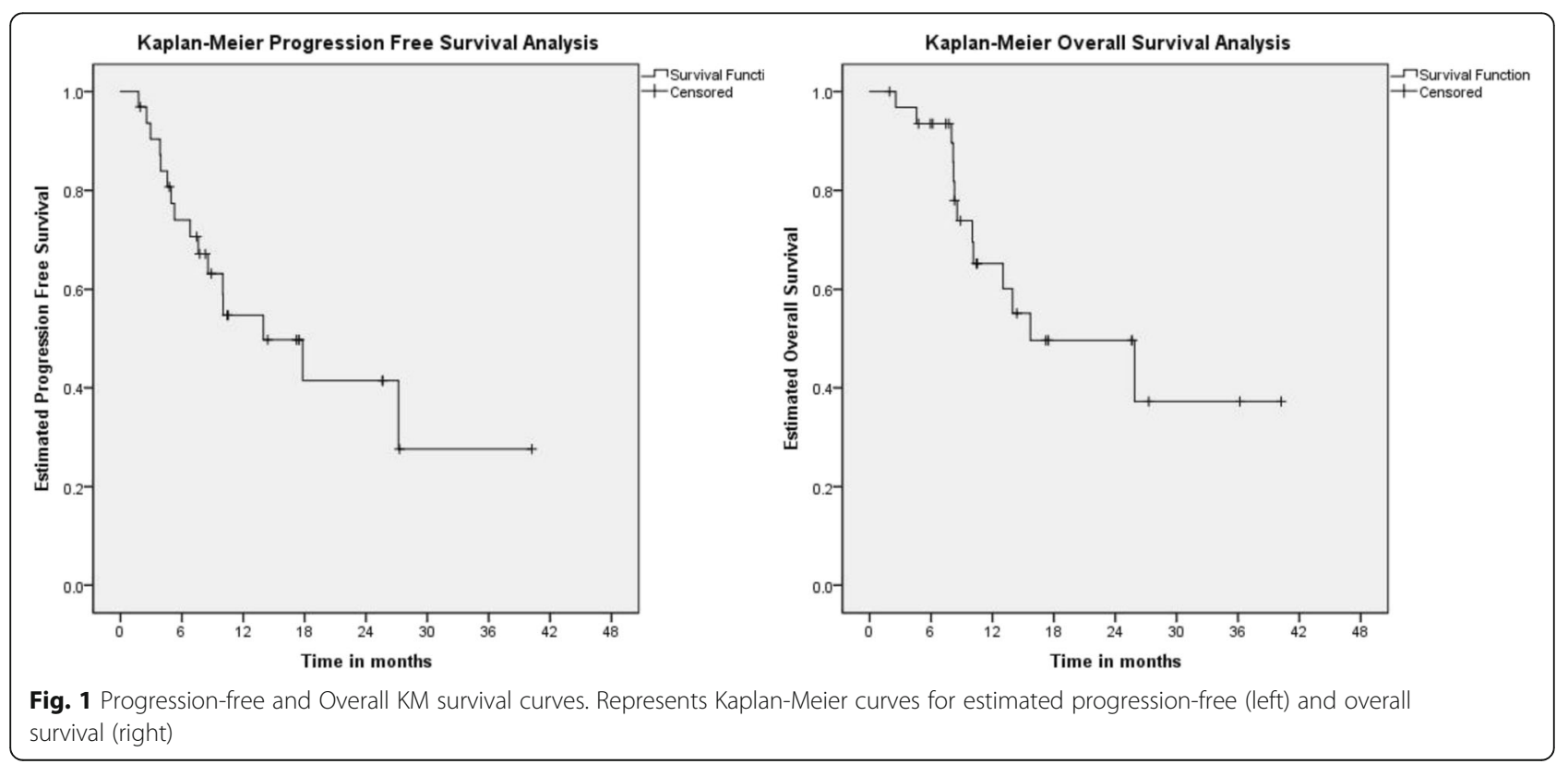




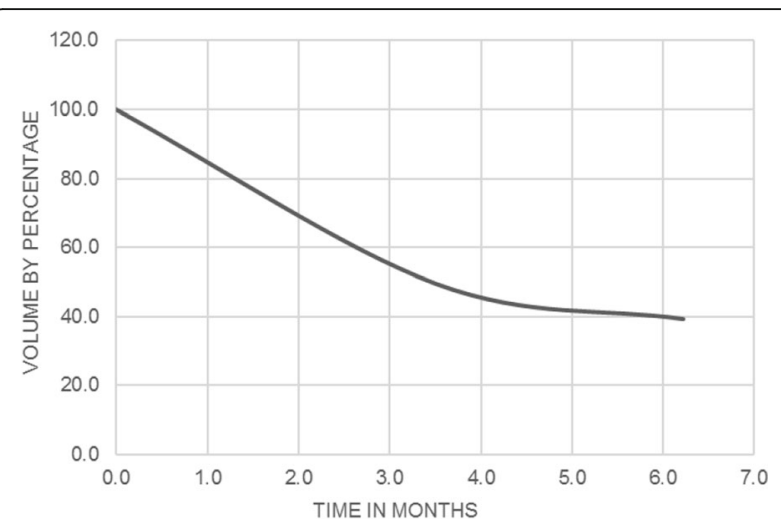

Fig. 2 Tumor volumes response. Represents tumor volume reduction in percentage as a response to treatment overtime

Table 4 Reported High-grade toxicity

\begin{tabular}{|c|c|c|c|}
\hline Toxicity & Grade & $n$ & $\%$ \\
\hline \multirow[t]{2}{*}{ Nausea } & Level-3 & 2 & 6.3 \\
\hline & Level-4 & 0 & 0.0 \\
\hline \multirow[t]{2}{*}{ Vomiting } & Level-3 & 2 & 6.3 \\
\hline & Level-4 & 0 & 0.0 \\
\hline \multirow[t]{2}{*}{ Diarrhea } & Level-3 & 2 & 6.3 \\
\hline & Level-4 & 0 & 0.0 \\
\hline \multirow[t]{2}{*}{ Anorexia } & Level-3 & 1 & 3.1 \\
\hline & Level-4 & 0 & 0.0 \\
\hline \multirow[t]{2}{*}{ Mouth soreness/Stomatitis } & Level-3 & 2 & 6.3 \\
\hline & Level-4 & 0 & 0.0 \\
\hline \multirow[t]{2}{*}{ Neuropathy/Numbness } & Level-3 & 0 & 0.0 \\
\hline & Level-4 & 0 & 0.0 \\
\hline \multirow[t]{2}{*}{ Fatigue/Weakness } & Level-3 & 4 & 12.5 \\
\hline & Level-4 & 0 & 0.0 \\
\hline \multirow[t]{2}{*}{ Rash } & Level-3 & 1 & 3.1 \\
\hline & Level-4 & 0 & 0.0 \\
\hline \multirow[t]{2}{*}{ Conjunctivitis } & Level-3 & 0 & 0.0 \\
\hline & Level-4 & 0 & 0.0 \\
\hline \multirow[t]{2}{*}{ Anaphylaxis } & Level-3 & 0 & 0.0 \\
\hline & Level-4 & 1 & 3.1 \\
\hline \multirow[t]{2}{*}{ Neutropenic fever/sepsis } & Level-3 & 0 & 0.0 \\
\hline & Level-4 & 0 & 0.0 \\
\hline \multirow[t]{2}{*}{ Neutropenia } & Level-3 & 6 & 18.8 \\
\hline & Level-4 & 1 & 3.1 \\
\hline \multirow[t]{2}{*}{ Thrombocytopenia } & Level-3 & 1 & 3.1 \\
\hline & Level-4 & 0 & 0.0 \\
\hline \multirow[t]{2}{*}{ Anemia } & Level-3 & 5 & 15.6 \\
\hline & Level-4 & 0 & 0.0 \\
\hline \multirow[t]{2}{*}{ AKI } & Level-3 & 0 & 0.0 \\
\hline & Level-4 & 0 & 0.0 \\
\hline
\end{tabular}

not cures. However, those patients who wish to avoid side effects from standard chemotherapy or have a performance status of $>1$ may not be eligible to receive these drugs first line. Even if patients could receive one or both of these drugs as first-line therapy a major question would this be an optimal treatment strategy.

It is common to see treating physicians reducing the dose of chemotherapy by certain percentage after toxicity becomes unbearable. However, by that time sometimes it is too late as a patient might not be able to tolerate any further chemotherapy or refuse any further treatment based on poor quality of life from chemotherapy-associated toxicity. This might lead to what we define as 'treatment failure' whereas those same patients might have responded well once their doses were lowered and toxicities become tolerable. Toxicities with standard doses are the main limiting factor for the number of cycles or duration of therapy given for any particular drug. We might be able to see full effects of the drug if they are given for longer duration, which requires controlling associated toxicity which in turn might need using lower doses than recommended.

With the approach we used in this study, instead of starting high dose and waiting for toxicity to decide when to lower the dose, we began low and then slowly raise the dose until we hit the boundary between acceptable and unacceptable toxicity for each patient and each drug. By starting low and then titrating the dose up based on response and tolerability, we were able to maximize the number of the cycle each patient could get and in turn received potentially the maximal benefit which could be afforded with these drugs. Initial doses were about $50 \%$ of standard doses and doses were then constantly titrated from thereon, considering each individual. Surprisingly many patients responded extremely well with lower doses and did not require full intensity chemotherapy. This stresses the important point that each individual has different chemo-sensitivity analogous to different toxicity in each individual with similar doses. This is probably a result of each patient's different ability of metabolism and excreting drug as well as the tolerance of each patient which is affected by each patient's comorbidities. Since lower dose chemotherapy has better tolerability, this allowed us to deliver a maximum of 14 chemotherapy as compared to a maximum of 4 (rarely 6) cycles for standard chemotherapy regimens with the same drugs in landmark studies $[5,7,11,14]$. Due to lower toxicity, the patient received uninterrupted and sustained chemotherapy (median of 6.2 months, range 1.8-21.1). This prolonged anti-neoplastic therapy revealed ultimate antitumor capability of these regimens in due course. Due to protracted therapy, we were able to reveal potential long-term benefits of these drugs in this patient population with advanced or metastatic disease. This is evident from 3 (9.4\%) 
patients achieving CR while another 1 patient achieving $\mathrm{nCR}$ despite having metastatic disease, to begin with.

There are several reasons why lower dose chemotherapy can be effective. First, recurrent and frequent lowdose chemotherapy over prolonged time causes tumor angiogenesis inhibition by endothelial cells inhibition or toxicity [33-35]. Also, T cells (Tregs) within tumors help to suppress the immune system from recognizing and attacking cancer. Low-dose frequent administration of chemotherapy selectively reduces these Treg cells and interferes with the immune-suppression function of these Treg cells (blocking their function) while not significantly interfering with the immune system, thereby unleashing the immune system to attack cancer similarly as checkpoint inhibitors [36-38]. Another mechanism which explains benefits from this low dose frequently repeated dosing is averting secretion of certain proteins by stromal cells in tumors which occur after high-intensity chemotherapy. These proteins are believed to be responsible for recurrence of aggressive forms of tumors from residual cells [28]. Metronomic chemotherapy not only targets the microenvironment of tumor cells but has also been noted to causes direct cytotoxicity from prolonged exposure to low concentrations of chemotherapy [39].

Another similar known approach is dose dense chemotherapy, a methodology where the dose is given but in a higher number of fractions. The approach is based in part on the understanding of Gompertzian growth curve, essentially small tumor grows rapidly hence are typically very sensitive to chemotherapy due to rapid acceleration. However, tumor growth rate plateaus or slows down over time as the tumor cells outgrow the available nutrients and blood supply essential for rapid growth. Since like normal cells, tumor cells recover and regrow several days after cytotoxic effects of chemotherapy vanishes and by hitting the tumor cells at this time when they are just beginning to grow rapidly again, chemotherapy becomes more effective. Hence, in low dose chemotherapy by fractionating 3 week dosing into weekly dosing, each weekly dose is better tolerated as the dose is much lower, but the effectiveness of therapy is increased by repeated dosing [40].

Although these studies performed by using a low dose or dose-dense or metronomic chemotherapy approach have varied schedules and doses, they have common underlying principle. By using these better-tolerated regimes, researchers have discovered other anti-tumor mechanism as discussed above in contrast to the direct cytotoxic effects of MTD based treatment regimens. We aimed to follow the same underlying principle and provided flexibility and individualization with low-dose and prolonged chemotherapy. This study also discovered another important point that surgical option, which was excluded at the first place due to advanced disease became an option once again after we were able to achieve a complete or near complete response. Due to this, $6(18.8 \%)$ patients went for surgical exploration to explore and eradicate any residual disease and thus giving further long-term benefits.

\section{Study limitations}

As with all retrospective studies, this study does have inherent limitations of a retrospective study. The main aim of this study was to provide evidence that lower doses of currently available regimens might be effective and can be individualized based on each patient and not to propose any new protocol. We did not perform any formal evaluation regarding the quality of life but patients in this study received a median of 9 cycles of chemotherapy, and low toxicity profile does give indirect evidence of better tolerability and thus better quality of life. Relatively small sample size of this study is another limitation.

\section{Conclusion}

These encouraging results along with low toxicity profile of this chemotherapy approach inspire us towards patient-tailored approach rather than one-size fits all approach, especially for palliative treatment.

\section{Abbreviations \\ 5-FU: 5-Flurouracil; AUC: Area under the curve; CR: Complete response; CTCAE: Common terminology criteria for adverse events; DCR: Disease control rate; ECOG: Eastern cooperative oncology group; EGFR: Epidermal growth factor receptor; FDA: Food and drug administration; KM: Kaplan meier; MTD: Maximum tolerated dose; NCCN: National comprehensive cancer network; NCR: Near complete response; ORR: Overall response rate; PCR: Pathologic complete; PD: Progressive disease; PFE: Platin, 5-FU, EGFR inhibitor; PFS: Progression free; PR: Partial response; QOL: Quality of life; SCCHN: Squamous cell carcinoma of the head and neck; SD: Stable disease; TPF: Taxol, Platin, and 5-FU}

\section{Acknowledgements \\ Not applicable}

Funding

No grant or other monetary sources were used to conduct this study.

\section{Availability of data and materials}

The datasets during and/or analyzed during the current study available from the corresponding author on reasonable request.

\section{Authors' contributions}

$\mathrm{RB}, \mathrm{CS}, \mathrm{HB}$ were involved in data collection, JB provided radiologic data, DR designed study and is principal investigator and mentor author. RB was a major contributor in writing manuscript. All authors read and approved the final manuscript.

\section{Ethics approval and consent to participate}

This study was approved by Institution Review Board (IRB) at University of Florida, Gainesville FL and all standard ethical guidelines were followed. Full waiver of informed consent was obtained. (IRB201500105).

Consent for publication

Not applicable. Manuscript does not contain any individual person's data.

Competing interests

The authors declare that they have no competing interests. 


\section{Publisher's Note}

Springer Nature remains neutral with regard to jurisdictional claims in published maps and institutional affiliations.

\section{Author details}

'Department of Medicine, University of Florida, PO Box 100238, Gainesville, Florida 32610-0238, USA. ²Baptist Medical Group - Hematology Oncology, 1717 North E Street Tower 3, Suite 231, Pensacola 32501, Florida, USA. ${ }^{3}$ Department of Radiology, University of Florida, PO Box 100374, Gainesville, Florida 32610-0238, USA. ${ }^{4}$ Department of Medicine, University of Florida, PO Box 100278, 1600 SW Archer Rd, Gainesville, Florida 32610, USA.

Received: 9 August 2017 Accepted: 24 October 2017 Published online: 14 December 2017

\section{References}

1. Siegel RL, Miller KD, Jemal A. Cancer statistics, 2017. CA Cancer J Clin. 2017; 67(1):7-30.

2. Pulte $\mathrm{D}$, Brenner $\mathrm{H}$. Changes in survival in head and neck cancers in the late 20th and early 21st century: a period analysis. In: Oncologist, vol. 15; 2010. p. 994-1001.

3. Marur S, Forastiere AA. Head and neck Squamous cell carcinoma: update on epidemiology, diagnosis, and treatment. 2016, 91(3):386-396.

4. Argiris A, Harrington KJ, Tahara M, Schulten J, Chomette P, Ferreira Castro A, Licitra L. Evidence-based treatment options in recurrent and/or metastatic Squamous cell carcinoma of the head and neck. Front Oncol. 2017:7

5. Vermorken JB, Stohlmacher-Williams J, Davidenko I, Licitra L, Winquist E, Villanueva C, Foa P, Rottey S, Skladowski K, Tahara M, et al. Cisplatin and fluorouracil with or without panitumumab in patients with recurrent or metastatic squamous-cell carcinoma of the head and neck (SPECTRUM): an open-label phase 3 randomised trial. Lancet Oncol. 2013;14(8):697-710.

6. Vermorken JB, Mesia R, Rivera F, Remenar E, Kawecki A, Rottey S, Erfan J, Zabolotnyy D, Kienzer HR, Cupissol D, et al. Platinum-based chemotherapy plus cetuximab in head and neck cancer. N Engl J Med. 2008;359

7. Vermorken JB, Mesia R, Rivera F, Remenar E, Kawecki A, Rottey S, Erfan J, Zabolotnyy D, Kienzer HR, Cupissol D, et al. Platinum-based chemotherapy plus cetuximab in head and neck cancer. N Engl J Med. 2008:359(11):1116-27.

8. Sacco AG, Cohen EE. Current treatment options for recurrent or metastatic head and neck Squamous cell carcinoma. J Clin Oncol. 2015;33(29):3305-13.

9. Charalambakis N, Kouloulias V, Vaja H, Pectasides D, Rampias T, Economopoulos T, Katsaounis P, Siolos S, Bartzi V, Perisanidis C, et al. Feasibility of induction Docetaxel, Cisplatin, 5-fluorouracil, Cetuximab (TPF-C) followed by concurrent Cetuximab radiotherapy for locally advanced head and neck Squamous cell carcinoma. Front Oncol. 2013:3:5.

10. Vermorken JB, Remenar E, van Herpen C, Gorlia T, Mesia R, Degardin M, Stewart JS, Jelic S, Betka J, Preiss JH et al: Cisplatin, fluorouracil, and docetaxel in unresectable head and neck cancer. N Engl J Med 2007, 357(17):1695-1704.

11. Guigay J, Fayette J, Dillies AF, Sire C, Kerger JN, Tennevet I, Machiels JP, Zanetta S, Pointreau Y. Bozec le Moal L et al: Cetuximab, docetaxel, and cisplatin as first-line treatment in patients with recurrent or metastatic head and neck squamous cell carcinoma: a multicenter, phase II GORTEC study. Ann Oncol. 2015;26(9):1941-7.

12. Markowitz AJ, Rabow MW. Palliative care for patients with head and neck cancer: "I would like a quick return to a normal lifestyle". JAMA. 2008;299(22):2679.

13. Bishnoi R, Bennett J, Reisman DN. Palliative treatment of patients with inoperable locally advanced, recurrent or metastatic head and neck squamous cell cancer, using a low-dose and personalized chemotherapeutic regimen. Oncol Lett. 2017;13(6):4633-40.

14. Meeting Library | Phase II trial of combination treatment with paclitaxel, carboplatin and cetuximab (PCE) as first-line treatment in patients with recurrent and/or metastatic squamous cell carcinoma of the head and neck (CSPOR-HN02). J Clin Oncol. 2016;34(suppl; abstr 6026). [URL:https:// meetinglibrary.asco.org/record/126222/abstract]. 2016 ASCO Annual Meeting.

15. Cho H, Nishiike S, Yamamoto $Y$, Takenaka Y, Nakahara S, Yasui T, Hanamoto A, Inohara H. Docetaxel, cisplatin, and fluorouracil for patients with inoperable recurrent or metastatic head and neck squamous cell carcinoma. Auris Nasus Larynx. 2015:42(5):396-400.

16. Guntinas-Lichius O, Appenrodt S, Veelken F, Krug B. Phase II study of weekly docetaxel and cisplatin in patients with advanced recurrent and metastatic head and neck cancer. Laryngoscope. 2006;116(4):613-8.
17. Huang CE, Lu CH, Chen PT, Chan CH, Chen WC, Wang WH, Wu JY, Kuan FC, Lee KD, Chen CC. Efficacy and safety of dose-modified docetaxel plus cisplatin-based induction chemotherapy in Asian patients with locally advanced head and neck cancer. J Clin Pharm Ther. 2012;37(3):342-7.

18. Lin JT, Lai GM, Chang TH, Liu MT, Bi CP, Wang JW, Chen MK. Chemotherapy with modified docetaxel, cisplatin, and 5-fluorouracil in patients with metastatic head and neck cancer. Adv Ther. 2012;29(1):71-7.

19. Yossi S, Linot B, Peyraga G, Breheret R, Laccourreye L, Capitain O. Feasibility and safety of dose-dense modified docetaxel-cisplatin or carboplatin and 5-fluorouracil regimen (mTPF) in locally advanced or metastatic head and neck cancers: a retrospective monocentric study. Int J Clin Oncol. 2015;

20. Bishnoi R, Bennett JA, Reisman D. A low dose and individualized regimen for palliative treatment of head and neck squamous cell cancer. Am Soc Clin Oncol. 2016;

21. Specenier $P$, Rasschaert $M$, Vroman $P$, Van den Brande J, Dyck J, Schrijvers D, Huizing MT, Vermorken JB. Weekly docetaxel in patients with recurrent and/ or metastatic squamous cell carcinoma of the head and neck. Am J Clin Oncol. 2011;34(5):472-7.

22. Lien K, Georgsdottir S, Sivanathan L, Chan K, Emmenegger U. Low-dose metronomic chemotherapy: a systematic literature analysis. Eur J Cancer. 2013:49(16):3387-95.

23. De Felice F, Musio D, Tombolini V. Head and neck cancer: metronomic chemotherapy. BMC Cancer. 2015;15(1):677.

24. Mateen A, Adil AR, Maken RN, Khan SA, Arif M. Metronomic chemotherapy in recurrent head and neck cancer. J Clin Oncol. 2015;33(suppl 15):e17007_ e17007.

25. Romiti A, Cox MC, Sarcina l, et al. Metronomic chemotherapy for cancer treatment: a decade of clinical studies | SpringerLink. Cancer Chemother Pharmacol. 2013;72:13. https://doi.org/10.1007/s00280-013-2125-x.

26. Hanahan D, Bergers G, Bergsland E. Less is more, regularly: metronomic dosing of cytotoxic drugs can target tumor angiogenesis in mice. J Clin Invest. 2000;105(8):1045-7.

27. André N, Carré M, Pasquier E. Metronomics: towards personalized chemotherapy? Nat Rev Clin Oncol. 2014;11(7):413-31.

28. Chan T-S, Hsu C-C, Pai VC, Liao W-Y, Huang S-S, Tan K-T, Yen C-J, Hsu S-C, Chen W-Y, Shan Y-S et al: Metronomic chemotherapy prevents therapyinduced stromal activation and induction of tumor-initiating cells. J Exp Med. 2016:213(13):2967-88. doi:10.1084/jem.20151665.

29. Oken MM, Creech RH, Tormey DC, Horton J, Davis TE, McFadden ET, Carbone PP. Toxicity and response criteria of the eastern cooperative oncology group. Am J Clin Oncol. 1982;5(6):649-55.

30. Trotti A, Colevas AD, Setser A, Rusch V, Jaques D, Budach V, Langer C, Murphy B, Cumberlin R, Coleman CN, et al. CTCAE v3.0: development of a comprehensive grading system for the adverse effects of cancer treatment. Semin Radiat Oncol. 2003:13(3):176-81.

31. Eisenhauer EA, Therasse P, Bogaerts J, Schwartz LH, Sargent D, Ford R, Dancey J, Arbuck S, Gwyther S, Mooney M, et al. New response evaluation criteria in solid tumours: revised RECIST guideline (version 1.1). Eur J Cancer. 2009;45(2):228-47.

32. Seiwert TY, et al. Safety and clinical activity of pembrolizumab for treatment of recurrent or metastatic squamous cell carcinoma of the head and neck (KEYNOTE-012): an open-label, multicentre, phase 1b trial. Lancet Oncol. 2017;17(7):956-65

33. Pasquier $\mathrm{E}$, Kavallaris $\mathrm{M}$, André $\mathrm{N}$. Metronomic chemotherapy: new rationale for new directions. Nat Rev Clin Oncol. 2010;7

34. Kerbel RS, Kamen BA. The anti-angiogenic basis of metronomic chemotherapy. Nat Rev Cancer. 2004;4(6):423-36.

35. Bocci G, Nicolaou KC, Kerbel RS: Protracted low-dose effects on human endothelial cell proliferation and survival in vitro reveal a selective Antiangiogenic window for various chemotherapeutic drugs. Cancer Res. 2002;62(23):6938-43.

36. Ghiringhelli F, Menard C, Puig PE, Ladoire S, Roux S, Martin F, Solary E, Cesne A, Zitvogel L, Chauffert B. Metronomic cyclophosphamide regimen selectively depletes CD4 + CD25+ regulatory T cells and restores T and NK effector functions in end stage cancer patients. Cancer Immunol Immunother. 2007;56

37. Lutsiak MEC, Semnani RT, Pascalis RD, Kashmiri SVS, Schlom J, Sabzevari H: Inhibition of CD4+25+ T regulatory cell function implicated in enhanced immune response by low-dose cyclophosphamide. Blood. 2005;105(7):2862-68; doi:10.1182/blood-2004-06-2410.

38. Kareva I, Waxman DJ, Klement GL. Metronomic chemotherapy: an attractive alternative to maximum tolerated dose therapy that can activate anti-tumor immunity and minimize therapeutic resistance. Cancer Lett. 2015;358(2):100-6. 
39. André $\mathrm{N}$, et al. Chemotherapy: Direct Targeting of Cancer Cells after all? Trends Can. 2017;3(5):319-25.

40. OncoLink CRf, Treatment R, Coping, Clinical Trials, Prevention: Dose-Dense Chemotherapy | OncoLink. 2017. https://www.oncolink.org/healthcareprofessionals/o-pro-portal/articles-about-cancer-treatment-andmedications/ dose-dense-chemotherapy.

Submit your next manuscript to BioMed Central and we will help you at every step:

- We accept pre-submission inquiries

- Our selector tool helps you to find the most relevant journal

- We provide round the clock customer support

- Convenient online submission

- Thorough peer review

- Inclusion in PubMed and all major indexing services

- Maximum visibility for your research

Submit your manuscript at www.biomedcentral.com/submit 